\title{
Low vitamin D status is associated with hypothyroid Hashimoto's thyroiditis
}

\author{
Dohee Kim ${ }^{1,2}$
}

${ }^{1}$ Department of Internal Medicine, Dankook University College of Medicine, ${ }^{2}$ Department of Kinesiologic Medical Science, Graduate, Dankook University, Cheonan, 330-714, Republic of Korea

\begin{abstract}
OBJECTIVE: The association of low vitamin D status with autoimmune thyroid disease (AITD), which includes Hashimoto's thyroiditis (HT) and Graves' disease (GD), is controversial. The aim of this study was to investigate the correlation between vitamin D insufficiency and AITD, HT, and GD. DESIGN: Our cross-sectional study included patients who visited a tertiary hospital for thyroid evaluation or follow-up. A total of 776 patients in whom serum 25-hydroxyvitamin $D$ [25(OH)D], thyroid function, and anti-thyroid antibodies had been measured were analyzed retrospectively. Vitamin D insufficiency was defined as serum $25(\mathrm{OH}) \mathrm{D}$ level $<75 \mathrm{nmol} / \mathrm{L}$. RESULTS: The prevalence of vitamin D insufficiency was significantly higher in the 369 patients with AITD than in the 407 without AITD (46.1\% vs. 37.1\%, $p=0.011)$, and higher in the 221 patients with HT than in those with GD or non-AITD (48.9\% vs. 41.9\%,37.1\%, $p=0.017)$. Among HT cases, patients with overt hypothyroidism had a significantly higher prevalence of vitamin D insufficiency $(60.4 \%$ vs. $44.1 \%, 21.7 \%, 37.1 \%$, respectively, $p<0.001)$ and lower $25(\mathrm{OH}) \mathrm{D}$ levels $(80.1 \pm 47.7$ vs. $99.34 \pm 61.2,110.3 \pm 69.9,99.6 \pm 53.7 \mathrm{nmol} / \mathrm{L}$, respectively, $p=0.009)$ compared with those with euthyroidism and subclinical hypothyroidism or those without AITD. Serum 25(OH)D levels were significantly negatively correlated with serum thyroid stimulating hormone (TSH) levels after adjustment for age, sex, body mass index, and sampling season ( $\mathrm{r}=$ $\mathbf{- 0 . 1 2 7}, p=0.013)$. CONCLUSION: Vitamin D insufficiency was associated with AITD and HT, especially overt hypothyroidism. Low serum vitamin $D$ levels were independently associated with high serum TSH levels.
\end{abstract}

Key words: Autoimmune thyroid disease, Graves' disease, Hashimoto's thyroiditis, Vitamin D deficiency

Address for correspondence:

Dohee Kim, Division of Endocrinology, Department of Internal

Medicine, Dankook University College of Medicine,

119, Dandae-ro, Dongnam-gu, Cheonan-si, Chungnam,

330-714, Republic of Korea;

Tel.: 82-041-550-3934; Fax: 82-041-556-3256;

E-mail: dh9070@hanmail.net, dh9070@dankook.ac.kr

Received: 18-06-2015, Accepted: 23-03-2016

\section{INTRODUCTION}

Vitamin D is a steroid molecule that is mainly produced in the skin and regulates the expression of many genes. ${ }^{1}$ The main role of vitamin $\mathrm{D}$ is to control bone metabolism and calcium and phosphorus homeostasis. Vitamin D is also associated with non-skeletal roles, including those found in 
autoimmune diseases, infectious diseases, metabolic syndrome and its components, cardiovascular diseases, cancers, and all-cause mortality. ${ }^{1-3}$ Vitamin D deficiency is common worldwide. ${ }^{1}$ The serum circulating 25-hydroxyvitamin D [25(OH)D] level is used to evaluate vitamin D status in patients at risk for vitamin D deficiency. Vitamin D deficiency is usually defined as a $25(\mathrm{OH}) \mathrm{D}$ level $<50 \mathrm{nmol} / \mathrm{L}$ $(20 \mathrm{ng} / \mathrm{ml})$ and vitamin D insufficiency as a $25(\mathrm{OH})$ D level of $50-72.5 \mathrm{nmol} / \mathrm{L}(20-29 \mathrm{ng} / \mathrm{ml}){ }^{1,3,4}$

Epidemiological studies have indicated a significant association between decreased levels of serum $25(\mathrm{OH}) \mathrm{D}$ and increased incidence of several autoimmune diseases including type 1 diabetes mellitus (T1DM), rheumatoid arthritis (RA), systemic lupus erythematosus, multiple sclerosis (MS), and inflammatory bowel disease, while experimental data have shown that vitamin D supplementation can prevent or suppress these autoimmune diseases. ${ }^{1-3,5-7}$ Clinical trials have also demonstrated that vitamin D supplements in humans may prevent the development of T1DM, RA or MS when given prophylactically. ${ }^{1-3,5-7}$

Several studies have examined the relationship between low vitamin D levels and the prevalence of autoimmune thyroid disease (AITD) in humans, but the results have been conflicting. ${ }^{5,8}$ Some studies have revealed low serum $25(\mathrm{OH}) \mathrm{D}$ levels in patients with AITD, as vitamin D deficiency is correlated with the presence or high levels of antithyroid antibodies, abnormal thyroid function, increased thyroid volume, and increased thyroid stimulating hormone (TSH) levels. ${ }^{5-7,9-10}$ Other reports have yielded a weak or no association between low vitamin D levels and thyroid autoimmunity. ${ }^{8,11-13}$ In animal models, vitamin D administration in addition to cyclosporine effectively prevented the induction of experimental autoimmune thyroiditis, and vitamin D-deficient BALB/c mice developed persistent hyperthyroidism. ${ }^{5,13}$ A recent study showed that low serum 25(OH)D levels in euthyroid patients with HT were inversely correlated with serum anti-thyroid peroxidase (TPO) antibodies and that after 4 months of vitamin D supplementation in patients with $25(\mathrm{OH}) \mathrm{D}$ levels $<75 \mathrm{nmol} / \mathrm{L}$ (30 $\mathrm{ng} / \mathrm{mL}$ ) there was a significant decrease in serum anti-TPO levels. ${ }^{14}$ Considering the potential role of vitamin $\mathrm{D}$ in autoimmune diseases, the aim of this study is to examine vitamin D levels in patients with autoimmune thyroid diseases and the correlation between low vitamin D status and AITD [including Hashimoto's thyroiditis (HT) and Graves' disease (GD)], HT or GD, and thyroid function and thyroid autoantibodies.

\section{SUBJECTS AND METHODOLOGY}

\section{Subjects}

The medical records of patients who visited the endocrinology outpatient clinic of Dankook University Hospital for thyroid evaluation or follow-up by one endocrinologist from March 2005 to June 2009 were reviewed. Patients underwent a thyroid function tests, antithyroid antibodies, and serum 25(OH)D levels. The antibodies of interest were thyroid stimulating hormone receptor antibody (TSHR-Ab), indicating $\mathrm{GD}$, and TPO-Ab and thyroglobulin antibody (Tg$\mathrm{Ab}$ ), suggesting HT. Serum parathyroid hormone (PTH), calcium, and phosphorus were also measured in these patients. Patients with metabolic bone diseases, primary hyperparathyroidism, renal disorders, liver disorders or epilepsy treated by anticonvulsants or who were on other medications that might alter vitamin $\mathrm{D}$ metabolism were excluded.

A total of 1,008 patients were initially reviewed and patients with missing laboratory data $(n=165)$ and with diseases or medications affecting vitamin $\mathrm{D}$ metabolism $(n=6)$ were excluded. A further 61 subjects who had transient thyroid dysfunction but negative thyroid autoantibodies, such as subacute thyroiditis or nonthyroidal illness, were excluded. Finally, a total of 776 patients were enrolled and placed in the AITD or non-AITD group according to the presence of antithyroid antibodies. Of these, 369 subjects were diagnosed as having GD or HT (AITD) and 407 displayed normal thyroid function and negative thyroid autoantibodies as well as having no evidence of GD or HT (non-AITD, control). Most patients with nonAITD had thyroid nodules or diabetes mellitus. The 148 patients with GD were diagnosed according to typical symptoms and signs of thyrotoxicosis and TSHR-Ab positivity ( $>1.5 \mathrm{IU} / \mathrm{L})$ or increased uptake in the thyroid scan. The diagnosis of 221 patients with HT was based on TPO-Ab ( $>100 \mathrm{mIU} / \mathrm{L})$ or Tg-Ab positivity $(>70 \mathrm{mIU} / \mathrm{L})$. Patients with $\mathrm{HT}$ were also classified into three groups according to their thy- 
roid function status at the time of sampling. Overt hypothyroid patients were those with serum TSH $>10 \mathrm{mIU} / \mathrm{L}$ and free thyroxine (fT4) $<10.04 \mathrm{pmol} / \mathrm{L}$ $(0.78 \mathrm{ng} / \mathrm{dL})$, or those with levothyroxine replacement regardless of thyroid function status. Subclinical hypothyroid patients were those with normal serum fT4 [10.0-24.97 pmol/L (0.78-1.94 ng/dL)] and with elevated serum TSH levels within the range of 4-10 $\mathrm{mIU} / \mathrm{L}$. Euthyroid patients were those with normal serum fT4 and TSH levels (0.25-4.0 mIU/L). The study was approved by the institutional review board of Dankook University Hospital.

\section{Laboratory measurements}

Serum fT4 and TSH were measured using a fT4CTX radioimmunoassay (RIA) kit (Diasorin, Saluggia, Italy) and RIA-gnost ${ }^{\circledR}$ hTSH kit (Cisbio Bioassays, Codolet, France), respectively. Serum TSHR-Ab was determined using the TRAK human RIA (BRAHMS) kit (Thermo Scientific, Henningsdorf, Berlin, Germany). TPO-Ab and $\mathrm{Tg}-\mathrm{Ab}$ were measured using the TM Ab immunoradiometric assay (IRMA) CT kit (RADIM, Pomezia, Italy) and Tg-Ab using the one step CT RIA kit (RADIM). Serum concentrations of 25(OH)D were measured using a Roche Modular E170 Analyzer and an electrochemiluminescence immunoassay (ECLIA; Roche Diagnostics ${ }^{\circledR}$, Penzberg, Germany). Serum PTH levels were assessed using a total intact PTH IRMA kit (IBL international GMBH, Hamburg, Germany). Serum calcium, albumin, and phosphorus were measured using a model TBA200FR instrument (Toshiba Medical System, Tokyo, Japan). Corrected calcium levels were calculated on the basis of albumin levels. Vitamin D insufficiency and deficiency were defined as serum $25(\mathrm{OH}) \mathrm{D}$ levels $<75 \mathrm{nmol} / \mathrm{L}(30 \mathrm{ng} / \mathrm{mL})$ and $<50 \mathrm{nmol} / \mathrm{L}(20 \mathrm{ng} / \mathrm{mL})$, respectively.

\section{Statistical analyses}

All analyses were performed using SPSS software version 21.0 (SPSS, Chicago, IL, USA). Comparison of categorical variables between groups was done using the chi-square test. Continuous variables are expressed as mean \pm standard deviation. The Student's t-test and one-way ANOVA were used for comparison of continuous variables between two and more groups, respectively. Pearson's correlation analysis was performed to examine the correlation between vitamin $\mathrm{D}$ and biochemical variables. All $p$-values were two-sided and $p<0.05$ was considered statistically significant for all tests.

\section{RESULTS}

\section{Clinical and laboratory characteristics}

A total of 776 subjects ( 641 females and 135 males) were enrolled. The mean age was 45.4 years and the mean body mass index (BMI) was $23.6 \mathrm{~kg} /$ $\mathrm{m}^{2}$. The overall mean serum 25(OH)D level was 97.1 $\mathrm{nmol} / \mathrm{L}(38.9 \mathrm{ng} / \mathrm{mL})$. The prevalence of vitamin D insufficiency and deficiency was $41.4 \%$ and $16.2 \%$, respectively.

\section{Clinical and laboratory characteristics according to the presence of vitamin D insufficiency}

A comparison of the clinical characteristics of the vitamin D insufficiency [25(OH)D $<75 \mathrm{nmol} / \mathrm{L}$ $(30 \mathrm{ng} / \mathrm{mL})]$ and vitamin D sufficiency [25(OH)D $\geq 75 \mathrm{nmol} / \mathrm{L}(30 \mathrm{ng} / \mathrm{mL})$ ] groups is shown in Table 1. Patients with vitamin $D$ insufficiency $(n=352)$ were significantly younger and more predominantly female and had a lower BMI than those with vitamin D sufficiency. The serum PTH levels in patients with vitamin D insufficiency were significantly higher than those with vitamin D sufficiency, but there were no differences in serum calcium and phosphorus levels. The vitamin D insufficiency group had a significantly higher TSH level and prevalence of thyroid autoantibody positivity than the vitamin D sufficiency group, but there were no significant differences in $\mathrm{fT} 4$, TPO$\mathrm{Ab}$, and $\mathrm{Tg}-\mathrm{Ab}$ titres.

\section{Clinical and laboratory characteristics according to the presence of AITD}

Among the 776 patients, 369 subjects were diagnosed as having AITD (148 patients with GD, 221 patients with HT) and 407 as non-AITD. The baseline characteristics of AITD and non-AITD patients are compared in Table 2. Patients with AITD were significantly younger and had a lower BMI and higher serum PTH and corrected calcium levels than those with non-AITD. The mean serum 25(OH)D levels in patients with AITD $[94.6 \pm 56.7 \mathrm{nmol} / \mathrm{L}$ (37.9 $\pm 22.7 \mathrm{ng} / \mathrm{mL})$ ] had a tendency to be lower than in those with non-AITD $[99.6 \pm 53.9 \mathrm{nmol} / \mathrm{L}(39.9 \pm$ 
Table 1. The characteristics based on vitamin D insufficiency

\begin{tabular}{|c|c|c|c|}
\hline & $\begin{array}{c}\text { Vitamin D insufficiency } \\
{[25(\mathrm{OH}) \mathrm{D}<75 \mathrm{nmol} / \mathrm{L}](\mathrm{n}=321)}\end{array}$ & $\begin{array}{c}\text { Vitamin D sufficiency } \\
{[25(\mathrm{OH}) \mathrm{D} \geq 75 \mathrm{nmol} / \mathrm{L}](\mathrm{n}=455)}\end{array}$ & $P$-value \\
\hline Age (years) & $43.7 \pm 15.2$ & $46.7 \pm 13.4$ & 0.004 \\
\hline Female gender [n (\%)] & $290(90.3 \%)$ & $351(77.1 \%)$ & 0.000 \\
\hline Body mass index $\left(\mathrm{kg} / \mathrm{m}^{2}\right)$ & $23.2 \pm 3.4$ & $24.0 \pm 3.7$ & 0.002 \\
\hline PTH (ng/L) & $32.4 \pm 21.9$ & $27.2 \pm 13.6$ & 0.000 \\
\hline Calcium (mmol/L) & $2.28 \pm 0.13$ & $2.28 \pm 0.13$ & 0.395 \\
\hline Phosphorus (mmol/L) & $1.29 \pm 0.23$ & $1.26 \pm 0.23$ & 0.162 \\
\hline fT4 (pmol/L) & $19.1 \pm 13.3$ & $19.7 \pm 12.0$ & 0.501 \\
\hline TSH (mIU/L) & $5.2 \pm 12.0$ & $3.2 \pm 7.3$ & 0.006 \\
\hline TSHR-Ab (IU/L) & $6.6 \pm 54.5$ & $4.1 \pm 15.8$ & 0.363 \\
\hline TPO-Ab (mIU/L) & $269.0 \pm 643.0$ & $199.8 \pm 496.2$ & 0.117 \\
\hline Tg-Ab (mIU/L) & $190.9 \pm 430.1$ & $145.2 \pm 354.1$ & 0.204 \\
\hline Prevalence of TPO- or Tg-Ab positivity [n (\%)] & $145(45.6)$ & $169(37.1)$ & 0.019 \\
\hline
\end{tabular}

Data are mean \pm standard deviation.

Calcium was corrected calcium. Bold values were $p<0.05$.

25(OH)D, 25-hydroxyvitamin D; PTH, parathyroid hormone; fT4, free thyroxine; TSH, thyroid stimulating hormone; TSHR-Ab, TSH receptor antibody; TPO-Ab, thyroid peroxidase antibody; Tg-Ab, thyroglobulin antibody.

Table 2. The characteristics based on the presence of autoimmune thyroid disease (AITD)

\begin{tabular}{|c|c|c|c|}
\hline & $\operatorname{AITD}(n=369)$ & Non-AITD $(n=407)$ & P-value \\
\hline Age (years) & $41.9 \pm 14.4$ & $48.6 \pm 13.3$ & 0.000 \\
\hline Female gender $[\mathrm{n}(\%)]$ & $310(84.0 \%)$ & $331(81.3 \%)$ & 0.325 \\
\hline Body mass index $\left(\mathrm{kg} / \mathrm{m}^{2}\right)$ & $23.2 \pm 3.5$ & $24.0 \pm 3.7$ & 0.001 \\
\hline 25(OH)D (nmol/L) & $94.6 \pm 56.7$ & $99.6 \pm 53.9$ & 0.195 \\
\hline Prevalence of vitamin D insufficiency [n (\%)] & $170(46.1 \%)$ & $151(37.1)$ & 0.011 \\
\hline PTH (ng/L) & $31.0 \pm 20.2$ & $27.8 \pm 14.9$ & 0.012 \\
\hline Calcium (mmol/L) & $2.30 \pm 0.13$ & $2.25 \pm 0.15$ & 0.000 \\
\hline Phosphorus (mmol/L) & $1.29 \pm 0.23$ & $1.26 \pm 0.23$ & 0.521 \\
\hline fT4 (pmol/L) & $23.2 \pm 16.7$ & $15.5 \pm 3.9$ & 0.000 \\
\hline TSH (mIU/L) & $5.4 \pm 11.9$ & $2.8 \pm 6.6$ & 0.000 \\
\hline TSHR-Ab (IU/L) & $9.9 \pm 52.1$ & $0.4 \pm 0.2$ & 0.000 \\
\hline TPO-Ab (mIU/L) & $443.1 \pm 735.6$ & $14.3 \pm 17.8$ & 0.000 \\
\hline Tg-Ab (mIU/L) & $336.6 \pm 520$ & $16.7 \pm 26.6$ & 0.000 \\
\hline
\end{tabular}

Data are mean \pm standard deviation.

Calcium was corrected calcium. Bold values were $p<0.05$.

25(OH)D, 25-hydroxyvitamin D; PTH, parathyroid hormone; fT4, free thyroxine; TSH, thyroid stimulating hormone; TSHR-Ab, TSH receptor antibody; TPO-Ab, thyroid peroxidase antibody; Tg-Ab, thyroglobulin antibody.

$21.6 \mathrm{ng} / \mathrm{mL})$ ], but the difference was not significant $(p>0.05)$. The prevalence of vitamin D insufficiency in patients with AITD was significantly higher than in those with non-AITD (46.1\% vs. $37.1 \%, p=0.011)$.
Serum 25(OH)D levels and the prevalence of vitamin D insufficiency according to the presence and the severity of $\mathrm{HT}$

There were no differences among $25(\mathrm{OH}) \mathrm{D}$ levels 
of patients with HT [ $92.1 \pm 57.4 \mathrm{nmol} / \mathrm{L}(36.9 \pm 23.0$ $\mathrm{ng} / \mathrm{mL})]$, GD $[98.1 \pm 54.9 \mathrm{nmol} / \mathrm{L}(39.3 \pm 22.0 \mathrm{ng} / \mathrm{mL})]$, and non-AITD $[99.6 \pm 53.7 \mathrm{nmol} / \mathrm{L}(39.9 \pm 21.5 \mathrm{ng} /$ $\mathrm{mL})$ ], but patients with HT had a tendency for lower levels of $25(\mathrm{OH}) \mathrm{D}$ than other groups $(p>0.05$; Figure $1 \mathrm{~A})$. The prevalence of vitamin D insufficiency in patients with HT was significantly higher than in those with GD or non-AITD (48.9\% vs. $41.9 \%$ or $37.1 \%$, $p=0.017$; Figure 1B). Patients with HT were further classified into three groups according to their thyroid function status at the time of sampling: euthyroid $(n=102)$, subclinical hypothyroid $(n=23)$, and overt hypothyroid patients $(n=96)$. There were significant differences between the 25(OH)D levels of the three HT groups and the non-AITD group ( $p=0.009$; Table 3 and Figure 2A). Overt hypothyroid patients with HT had significantly lower 25(OH)D levels than those with non-AITD $(p=0.010)$, but there were no
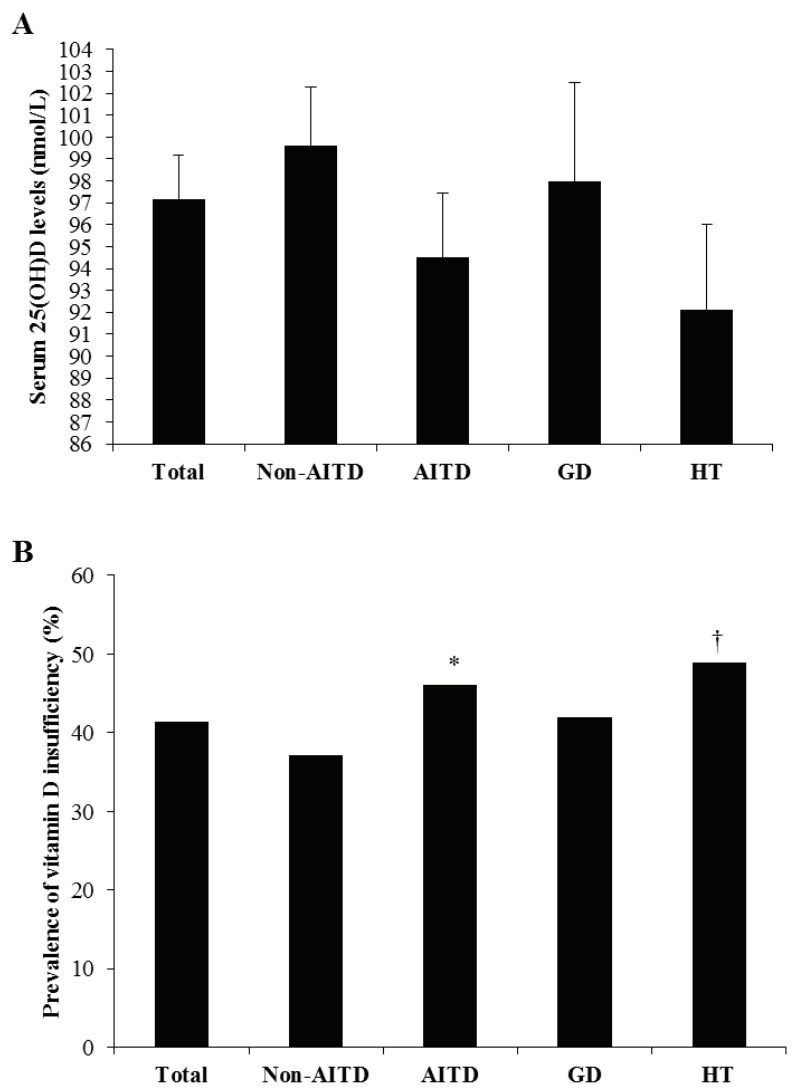

Figure 1. The mean serum 25(OH)D levels (A) and the prevalence of vitamin D insufficiency (B) according to thyroid diseases. AITD, autoimmune thyroid disease; GD, Graves' disease; HT, Hashimoto's thyroiditis. ${ }^{*} p<0.05$ vs. non-AITD, ${ }^{* *} p<0.01$ vs. non-AITD.
Table 3. Serum 25(OH)D levels and the prevalence of vitamin D insufficiency according to the presence and the severity of Hashimoto's thyroiditis (HT)

\begin{tabular}{lcc}
\hline & $\begin{array}{c}\mathbf{2 5}(\mathbf{O H}) \mathbf{D} \\
\mathbf{( n m o l} / \mathbf{L})\end{array}$ & $\begin{array}{c}\text { Vitamin D } \\
\text { insufficiency (\%) }\end{array}$ \\
\hline Non-AITD $(\mathrm{n}=555)$ & $99.6 \pm 53.7$ & 37.1 \\
HT with ET $(\mathrm{n}=102)$ & $99.34 \pm 61.2$ & 44.1 \\
HT with SCH $(\mathrm{n}=23)$ & $110.3 \pm 69.9$ & 21.7 \\
HT with OH $(\mathrm{n}=96)$ & $80.1 \pm 47.7^{*}$ & 60.4 \\
$P$-value between groups & 0.009 & 0.000 \\
\hline
\end{tabular}

$25(\mathrm{OH}) \mathrm{D}$ levels are mean \pm standard deviation

$* p=0.010$ vs. non-AITD

25(OH)D, 25-hydroxyvitamin D; AITD, autoimmune thyroid disease; ET, euthyroidism; SCH, subclinical hypothyroidism; $\mathrm{OH}$, overt hypothyroidism.
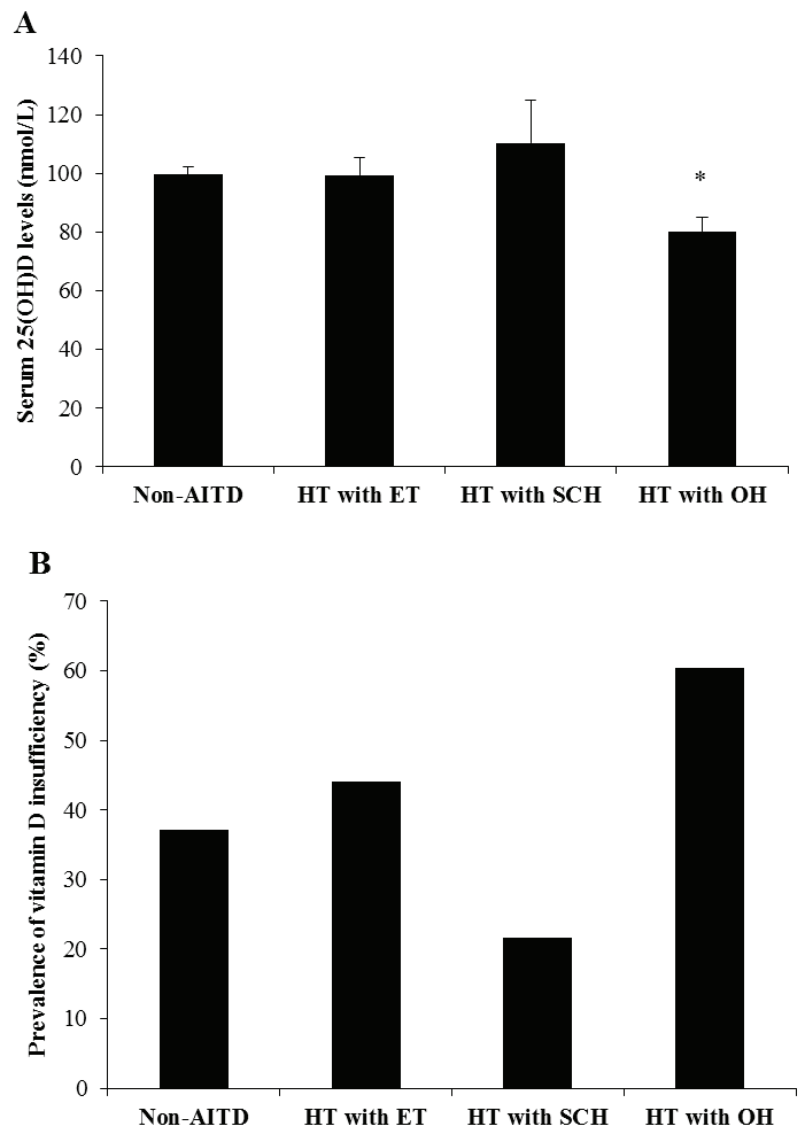

Figure 2. The mean serum 25(OH)D levels (A) and the prevalence of vitamin D insufficiency (B) according to the presence of Hashimoto's thyroiditis and thyroid function state in patients with Hashimoto's thyroiditis. HT, Hashimoto's thyroiditis; ET, euthyroidism; $\mathrm{SCH}$, subclinical hypothyroidism; OH, overt hypothyroidism. ${ }^{*} p<0.05$ vs. non-AITD, $p=0.009$ between groups (A), $p<0.001$ between groups (B). 
differences in 25(OH)D levels between other groups. Similarly, the prevalence of vitamin D insufficiency was significantly higher in overt hypothyroid patients with HT than in euthyroid and subclinical hypothyroid patients with HT and in those with non-AITD $(60.4 \%$ vs. $44.1 \%, 21.7 \%$, and $37.1 \%$, respectively, $p<0.001$; Table 3 and Figure 2B).

\section{Relationship between vitamin D levels and other biochemical variables}

The vitamin D status in each season of blood collection differed significantly $(p<0.001)$ and serum $25(\mathrm{OH}) \mathrm{D}$ levels in summer [June to August, $\mathrm{n}=182$, $102.8 \pm 55.7 \mathrm{nmol} / \mathrm{L}(41.2 \pm 22.3 \mathrm{ng} / \mathrm{mL}), \mathrm{p}=0.003 \mathrm{vs}$. winter, $p<0.001 \mathrm{vs}$. spring] and autumn [September to November, $\mathrm{n}=174,116.3 \pm 56.9 \mathrm{nmol} / \mathrm{L}(46.6 \pm$ $22.8 \mathrm{ng} / \mathrm{mL}), p<0.001$ vs. spring and winter] were higher than in spring [March to May, $\mathrm{n}=260,89.6 \pm$ $54.7 \mathrm{nmol} / \mathrm{L}(35.9 \pm 21.9 \mathrm{ng} / \mathrm{mL})]$ and winter [December to February, $\mathrm{n}=160,82.4 \pm 46.4 \mathrm{nmol} / \mathrm{L}$ (33.0 $\pm 18.6 \mathrm{ng} / \mathrm{mL})]$. Serum 25(OH)D levels were also significantly negatively correlated with serum TSH levels after adjustment for sample season as well as age, sex, and BMI $(r=-0.127, p=0.013)$.

\section{DISCUSSION}

In the present study, the vitamin D insufficiency group had a significantly higher TSH level and prevalence of thyroid autoantibody positivity than the vitamin D sufficiency group. A significantly higher prevalence of vitamin D insufficiency was evident in patients with AITD, and particularly HT, than in those with non-AITD. Overt hypothyroid patients with HT had a significantly higher prevalence of vitamin D insufficiency and lower 25(OH)D levels than euthyroid or subclinical hypothyroid patients with HT or those with non-AITD. Lower serum 25(OH)D levels were associated with higher TSH levels after adjustment for age, sex, BMI, and sampling season. Taken together, these data suggest an association between vitamin D insufficiency and the pathogenesis of AITD, especially HT.

AITD is the most common organ-specific autoimmune disorder that causes several forms of disease ranging from hypothyroidism (HT) to hyperthyroidism (GD) ${ }^{15-17}$ AITD is characterized by lymphocytic infiltration in the thyroid gland and the production of pathogenic thyroid autoantibodies. ${ }^{15}$ Pathogenesis of AITD is multifactorial, combining genetic, immune, environmental, and hormonal influences like vitamin D. ${ }^{5}$ In genetically predisposed individuals, the disruption of these neuroendocrine-immune interactions by environmental factors results in thyroid autoimmune dysfunction. ${ }^{17}$ These interactions are able to shift the balance between type $1 \mathrm{~T}$ helper (Th1)-Th2 immune response, resulting in a Th1cell-mediated autoimmune reaction with thyrocyte destruction and hypothyroidism in HT, but to a hyperreactive Th2-mediated humoral response against TSH receptor with stimulatory antibodies leading to GD hyperthyroidism. ${ }^{17}$ The mechanism underlying the link between vitamin $\mathrm{D}$ and autoimmunity is not completely understood but is probably associated with its anti-inflammatory and immunomodulatory functions. ${ }^{13,14}$ The expression of the nuclear vitamin D receptor (VDR) and the vitamin-D-activating enzyme $1 \alpha$-hydroxylase (CYP27B1) in most immune cells, including T cells, B cells, and antigen-presenting cells (APCs) including macrophages and dendritic cells (DCs), highlighted the potential involvement of vitamin $\mathrm{D}$ in the immune system and in the pathogenesis of autoimmune diseases. ${ }^{18-21}$ The active form of vitamin D, 1,25-dihydroxyvitamin D [1,25(OH)2D], inhibits the adaptive immune system. 1,25(OH)2D suppresses the proliferation, immunoglobulin production, and differentiation of B cells into plasma cells and promotes the apoptosis of immunoglobulin-producing $\mathrm{B}$ cells directly or indirectly mediated by helper $\mathrm{T}$ cells. ${ }^{19} \mathrm{In}$ addition, $1,25(\mathrm{OH}) 2 \mathrm{D}$ has direct regulatory effects on $\mathrm{T}$ cell proliferation and cytokine production. ${ }^{13,21} 1,25(\mathrm{OH}) 2 \mathrm{D}$ inhibits the proliferation of Th1 cells and the production of Th1 cytokines, such as interferon-gamma, interleukin (IL)-2, and IL-12. ${ }^{21}$ $1,25(\mathrm{OH}) 2 \mathrm{D}$ enhances the development of Th2 cells by exerting a direct effect on native CD4+ cells or by acting on $\mathrm{APC} / \mathrm{DC}$ and thus facilitating the production of Th2 cytokines, such as IL-4, IL-5, and IL-10, which move $\mathrm{T}$ differentiation in favour of the Th2 phenotype. 1,25(OH)2D also induces CD4+CD25+ regulatory $\mathrm{T}$ cells that produce IL-10, which leads to blocked development of Th1 cells and inhibited secretion of IL-17 by T-effector cells. ${ }^{13}$ Recently, several genetic studies demonstrated an association 
between susceptibility to thyroid autoimmunity and gene polymorphisms of numerous proteins and enzymes associated with vitamin D functions, including VDR, vitamin D binding protein (DBP), CYP27B1, and 25-hydroxylase (CYP2R1).

Several clinical studies have shown low vitamin D status in patients with AITD or HT, indicating an association between vitamin D deficiency and thyroid autoimmunity, which is consistent with the current study. ${ }^{5,6,9,10,14,22-25}$ Kivity et al. reported that the prevalence of vitamin D deficiency [serum $25(\mathrm{OH})$ D levels $<25 \mathrm{nmol} / \mathrm{L}(10 \mathrm{ng} / \mathrm{mL})$ ] was higher in patients with AITD compared with healthy individuals, as well as in patients with HT compared to patients with non-AITD, and vitamin D deficiency was also correlated with the presence of antithyroid antibodies and abnormal thyroid function tests, suggesting the involvement of vitamin $\mathrm{D}$ in the pathogenesis of AITD. ${ }^{5}$ Bozkurt et al. demonstrated that serum $25(\mathrm{OH}) \mathrm{D}$ levels of HT patients were significantly lower than those in controls and that the severity of $25(\mathrm{OH}) \mathrm{D}$ deficiency correlated with the duration of HT, thyroid volume, and antibody levels, suggesting a potential role of $25(\mathrm{OH}) \mathrm{D}$ in the development of HT and/or its progression to hypothyroidism. ${ }^{6}$ Other studies also showed lower serum 25(OH)D levels or a higher prevalence of vitamin D insufficiency in AITD or $\mathrm{HT}^{9,10}$ and a negative correlation between $25(\mathrm{OH})$ D and TPO-Ab levels in AITD or HT. ${ }^{9,14,22}$ In a recent Chinese population-based health survey, a negative correlation was found between $25(\mathrm{OH}) \mathrm{D}$ levels and $\mathrm{Tg}$-Ab levels in female individuals. ${ }^{23}$ Additionally, a few studies have reported an inverse relationship between $25(\mathrm{OH}) \mathrm{D}$ and TSH levels or severity in $\mathrm{HT}$, as in the present study, suggesting the association between low vitamin $\mathrm{D}$ status and progressive thyrocyte damage. ${ }^{6,10,24,25}$ The prevalence of vitamin $\mathrm{D}$ insufficiency [serum 25(OH)D levels $<75 \mathrm{nmol} / \mathrm{L}$ $(30 \mathrm{ng} / \mathrm{mL})]$ in HT showed a tendency to be higher in patients with overt or subclinical hypothyroidism than in those with euthyroidism. ${ }^{10}$ There was a significant inverse association between serum $25(\mathrm{OH})$ D levels and HT after adjustment for age, sex, and BMI. ${ }^{24}$ Vitamin D deficiency [serum 25(OH)D levels $<25 \mathrm{nmol} / \mathrm{L}(10 \mathrm{ng} / \mathrm{mL})]$ was strongly associated with higher TSH levels after adjusting for sex, age, and sample season in euthyroid adults. ${ }^{25} \mathrm{~A}$ recent meta-analysis of 20 case-control studies showed that AITD patients have lower levels of $25(\mathrm{OH}) \mathrm{D}$ and are more likely to be deficient in 25(OH)D compared to controls. ${ }^{26}$ Subgroup analyses showed that GD and HT patients also have lower 25(OH)D levels and are more likely to have $25(\mathrm{OH}) \mathrm{D}$ deficiency. ${ }^{26}$ The criterion for vitamin D deficiency in studies in this meta-analysis was $25(\mathrm{OH}) \mathrm{D}$ level $<25-50 \mathrm{nmol} / \mathrm{L}$ $(10-20 \mathrm{ng} / \mathrm{mL})$. In the current study, the association of AITD and vitamin D deficiency using a criterion of $25(\mathrm{OH}) \mathrm{D}$ level $<50 \mathrm{nmol} / \mathrm{L}(20 \mathrm{ng} / \mathrm{mL})$ was also analyzed, but there was no significant difference (data not shown). However, other studies showed no association between low vitamin D status and thyroid autoimmunity. ${ }^{11-13}$ It is unclear whether the low 25(OH)D levels observed in AITD or HT are the result of the autoimmune disease process or part of its cause. ${ }^{5,8,14}$ Low vitamin D levels in other autoimmune diseases can be explained by malabsorption, or by lack of sun exposure due to skin involvement or photosensitivity, or by reduced outdoor activity and chronic corticosteroid treatment. ${ }^{5,8,14}$ Several HT patients have a comorbid autoimmune disorder, or thyroid dysfunction, or other causes that could affect the production, absorption, and utilization of vitamin D. ${ }^{5,8,14}$

In the present study, vitamin D insufficiency did not increase the risk of GD. In a prior study, the prevalence of $25(\mathrm{OH}) \mathrm{D}<25 \mathrm{nmol} / \mathrm{L}(10 \mathrm{ng} / \mathrm{mL})$ in patients with GD was higher than in healthy controls, but was not significantly different compared to that in non-AITD. ${ }^{5}$ Other authors reported that vitamin $\mathrm{D}$ levels were no lower in patients with GD than in healthy controls. ${ }^{13}$ In contrast, others found that serum vitamin D levels were lower and associated with thyroid volume in female patients with new onset Graves' disease $^{7}$ and that serum vitamin $\mathrm{D}$ levels were lower in patients without remission of Graves' disease. ${ }^{27} \mathrm{~A}$ recent study revealed that serum vitamin $\mathrm{D}$ levels in TSHR-Ab-positive GD patients were lower than in healthy controls or TSHR-Ab-negative patients and inversely correlated with TSHR-Ab titre..$^{28}$ In addition to the aforementioned meta-analysis, another metaanalysis of 26 studies showed that patients with GD are more likely to be deficient in vitamin D compared to controls with a high heterogeneity. ${ }^{29}$ The relationship between vitamin $\mathrm{D}$ status and the severity, onset or 
presence of remission of GD were not further analyzed in the current study. The conflicting results regarding the correlation between vitamin D and AITD, HT or GD are in part due to cross-sectional studies with a small number of subjects, the heterogeneity of the study population, seasonal variation in blood sampling, inter-method analytical variability of vitamin D assays, and different definitions of vitamin D deficiency/insufficiency. ${ }^{13,14}$

The current study found the same pattern of seasonal variations in vitamin $\mathrm{D}$ levels as shown in a previous study.$^{30}$ However, after adjusting for sampling season as well as age, sex, and BMI, a negative correlation was also found between serum $25(\mathrm{OH}) \mathrm{D}$ and TSH levels, similarly to a prior study. ${ }^{25}$ The present study reported a relatively high mean vitamin $\mathrm{D}$ level and low prevalence of vitamin D insufficiency and deficiency compared to other Korean population-based studies. ${ }^{22,30}$ One of the Korean studies reported that the mean serum level of $25(\mathrm{OH}) \mathrm{D}$ was $52.9 \mathrm{nmol} / \mathrm{L}$ $(21.2 \mathrm{ng} / \mathrm{mL})$ in males (aged $10-91$ years) and 45.4 $\mathrm{nmol} / \mathrm{L}(18.2 \mathrm{ng} / \mathrm{mL})$ in females ranging in age from 10-93 years, while vitamin D insufficiency/deficiency was found in $86.8 \% / 47.3 \%$ of males and $93.3 \% / 64.5 \%$ of females by the Fourth Korea National Health and Nutrition Examination Surveys in the Korean population in $2008 .^{30}$ In the current study, adult patients who visited a tertiary hospital for thyroid evaluation or follow-up were enrolled. These patients may have been proactive as regards their own health. Many subjects have also lived in rural areas, working in agriculture or spending much time in outdoor places. ${ }^{30}$

The present study has several limitations. There is the possibility of selection bias because subjects were selected from patients who visited a tertiary hospital and were sampled. This study only investigated cross-sectional data retrospectively. Therefore, the causal relationship between low vitamin D status and AITD could not be determined. Seasonal variations in blood sampling could have influenced the results because patient sampling was not done in a single season. However, serum 25(OH)D levels were negatively correlated with TSH levels after adjusting for sampling season.

In conclusion, vitamin D insufficiency was associated with AITD and HT as well as with progress of thyrocyte damage in HT. There was a negative correlation between vitamin D and TSH levels after controlling for age, sex, BMI, and sampling season. However, further randomized, controlled and prospective studies are needed to investigate whether vitamin D insufficiency is a causal factor in the pathogenesis of AITD or HT and whether vitamin D supplementation would be helpful in patients with these diseases.

\section{REFERENCES}

1. Makariou S, Liberopoulos EN, Elisaf M, Challa A, 2011 Novel roles of vitamin $\mathrm{D}$ in disease: What is new in 2011? Eur J Intern Med 22: 355-362.

2. Plum LA, DeLuca HF, 2010 Vitamin D, disease and therapeutic opportunities. Nat Rev Drug Discov 9: 941-955.

3. Holick MF, 2007 Vitamin D deficiency. N Engl J Med 357: 266-281.

4. Holick MF, Binkley NC, Bischoff-Ferrari HA, et al, 2011 Evaluation, treatment, and prevention of vitamin D deficiency: an endocrine society clinical practice guideline. J Clin Endocrinol Metab 96: 1911-1930.

5. Kivity S, Agmon-Levin N, Zisappl M, et al, 2011 Vitamin D and autoimmune thyroid diseases. Cell Mol Immunol 8: 243-247.

6. Bozkurt NC, Karbek B, Ucan B, et al, 2013 The association between severity of vitamin D deficiency and Hashimoto's thyroiditis. Endocr Pract 19: 479-484.

7. Yasuda T, Okamoto Y, Hamada N, et al, 2012 Serum vitamin D levels are decreased and associated with thyroid volume in female patients with newly onset Graves' disease. Endocrine 42: 739-741.

8. Mazokopakis EE, Kotsiris DA, 2014 Hashimoto's autoimmune thyroiditis and vitamin D deficiency. Current aspects. Hell J Nucl Med 17: 37-40.

9. Shin DY, Kim KJ, Kim D, Hwang S, Lee EJ, 2014 Low serum vitamin $\mathrm{D}$ is associated with anti-thyroid peroxidase antibody in autoimmune thyroiditis. Yonsei Med J 55: 476-481.

10. Tamer G, Arik S, Tamer I, Coksert D, 2011 Relative vitamin D insufficiency in Hashimoto's thyroiditis. Thyroid 21: 891-896.

11. Goswami R, Marwaha RK, Gupta N, et al, 2009 Prevalence of vitamin D deficiency and its relationship with thyroid autoimmunity in Asian Indians: a communitybased survey. Br J Nutr 102: 382-386.

12. Effraimidis G, Badenhoop K, Tijssen JG, Wiersinga WM, 2012 Vitamin D deficiency is not associated with early stages of thyroid autoimmunity. Eur J Endocrinol 167: 43-48.

13. D’Aurizio F, Villalta D, Metus P, Doretto P, Tozzoli R, 2015 Is vitamin D a player or not in the pathophysiol- 
ogy of autoimmune thyroid diseases? Autoimmun Rev 14: 363-369.

14. Mazokopakis EE, Papadomanolaki MG, Tsekouras KC, Evangelopoulos AD, Kotsiris DA, Tzortzinis AA, 2015 Is vitamin $\mathrm{D}$ related to pathogenesis and treatment of Hashimoto's thyroiditis? Hell J Nucl Med 18: 222-227.

15. Kawashima A, Tanigawa K, Akama T, Yoshihara A, Ishii N, Suzuki K, 2011 Innate immune activation and thyroid autoimmunity. J Clin Endocrinol Metab 96: 3661-3671.

16. Fountoulakis S, Tsatsoulis A, 2004 On the pathogenesis of autoimmune thyroid disease: a unifying hypothesis. Clin Endocrinol (Oxf) 60: 397-409.

17. Klecha AJ, Barreiro Arcos ML, Frick L, Genaro AM, Cremaschi G, 2008 Immune-endocrine interactions in autoimmune thyroid diseases. Neuroimmunomodulation 15: 68-75.

18. Baeke F, Takiishi T, Korf H, Gysemans C, Mathieu C, 2010 Vitamin D: modulator of the immune system. Curr Opin Pharmacol 10: 482-496.

19. Prietl B, Treiber G, Pieber TR, Amrein K, 2013 Vitamin $\mathrm{D}$ and immune function. Nutrients 5: 2502-2521.

20. Hewison M, 2012 An update on vitamin D and human immunity. Clin Endocrinol (Oxf) 76: 315-325.

21. Mathieu C, Adorini L, 2002 The coming of age of 1,25-dihydroxyvitamin $\mathrm{D}_{3}$ analogs as immunomodulatory agents. Trends Mol Med 8: 174-179.

22. Choi YM, Kim WG, Kim TY, et al, 2014 Low levels of serum vitamin D3 are associated with autoimmune thyroid disease in pre-menopausal women. Thyroid
24: 655-661.

23. Wang X, Zynat J, Guo Y, et al, 2015 Low serum vitamin $\mathrm{D}$ is associated with anti-thyroid-globulin antibody in female individuals. Int J Endocrinol 2015: 285290.

24. Mansournia N, Mansournia MA, Saeedi S, Dehghan J, 2014 The association between serum 25OHD levels and hypothyroid Hashimoto's thyroiditis. J Endocrinol Invest 37: 473-476.

25. Barchetta I, Baroni MG, Leonetti F, et al, 2015 TSH levels are associated with vitamin D status and seasonality in an adult population of euthyroid adults Clin Exp Med 15: 389-396.

26. Wang J, Lv S, Chen G, et al, 2015 Meta-analysis of the association between vitamin $\mathrm{D}$ and autoimmune thyroid disease. Nutrients 7: 2485-2498.

27. Yasuda T, Okamoto Y, Hamada N, et al, 2013 Serum vitamin $\mathrm{D}$ levels are decreased in patients without remission of Graves' disease. Endocrine 43: 230-232.

28. Zhang H, Liang L, Xie Z, 2015 Low vitamin D status is associated with increased thyrotropin-receptor antibody titer in Graves' disease. Endocr Pract 21: 258-263.

29. Xu MY, Cao B, Yin J, Wang DF, Chen KL, Lu QB, 2015 Vitamin D and Graves' disease: a meta-analysis update. Nutrients 7: 3813-3827.

30. Choi HS, Oh HJ, Choi H, et al, 2011 Vitamin D insufficiency in Korea-a greater threat to younger generation: the Korea National Health and Nutrition Examination Survey (KNHANES) 2008. J Clin Endocrinol Metab 96: 643-651. 